\title{
Influence of diamond tool chamfer angle on surface integrity in ultra-precision turning of singe crystal silicon
}

\author{
Yigit Karpat ${ }^{1,2,3}$
}

Received: 11 June 2018 / Accepted: 18 November 2018 / Published online: 22 November 2018

(C) Springer-Verlag London Ltd., part of Springer Nature 2018

\begin{abstract}
Ultra precision diamond machining enables the economical production of freeform optics on infrared materials such as silicon. To produce optics with acceptable surface integrity, it is important to have a good understanding of process-work material interaction between diamond tool and brittle and hard single crystal IR materials. Chamfered cutting edges are known to have high strength, which makes them suitable for machining difficult-to-cut materials. This study investigates the influence of chamfer angle on the surface integrity of silicon. Diamond tool chamfer angles of $-20^{\circ},-30^{\circ}$, and $-45^{\circ}$ are considered under practical diamond turning conditions of single crystal silicon. State-of-the-art techniques were used to investigate the surface integrity of the machined silicon surfaces. The results show that chamfer angle of $30^{\circ}$ yields more favorable results compared to $20^{\circ}$ and $45^{\circ}$ under the conditions tested. The results indicate the complex interplay between tool geometry and process parameters in reaching an acceptable level of surface integrity. A machinability map indicating ductile and brittle machining conditions for $30^{\circ}$ chamfered diamond tool has been presented which includes directly transferable knowledge to the precision machining industry.
\end{abstract}

Keywords Diamond machining $\cdot$ Surface integrity $\cdot$ Silicon $\cdot$ Phase transformation

\section{Introduction}

Freeform optics offers a multitude of improvements over traditional spherical form optical systems [1]. A novel example would be compound eye systems, where the micro lenses are machined on curved substrate, mimicking the structure of a fly's eye as observed in nature. An active research subject is to obtain freeform optics on infrared (IR) materials and as a result extend the advantages of freeform optics beyond visible light applications [2-4]. Ultra precision diamond machining enables economical production of freeform optics made from IR materials. A good understanding of process-work material interaction between diamond cutting tool and brittle and hard

Yigit Karpat

ykarpat@bilkent.edu.tr

1 Department of Industrial Engineering, Bilkent University, Ankara, Turkey

2 Department of Mechanical Engineering, Bilkent University, Ankara, Turkey

3 UNAM-National Nanotechnology Research Center and Institute of Materials Science and Nanotechnology, Bilkent University, Ankara, Turkey single crystal IR materials such as silicon and germanium is important to the economical production of freeform optics with acceptable surface integrity.

Tool-work material engagement conditions change continuously due to the complex surface geometry of the freeform surfaces. Using slow slide servo technique to machine freeform optics requires the fragile diamond tool tip to work under interrupted machining conditions, which may lead to edge chipping [5]. Machining with chipped or worn diamond tools results in cracks on the machined surface, which hinders the surface integrity of the machined surface and adversely affects optical performance. Diamond cutting tools with chamfered edge preparations have the advantage of protecting the cutting edge from chipping [6]. Chamfered diamond tools have zero rake angle, but their cutting edges are chamfered at a specified angle and width. This study considers the influence of chamfer angle on the surface integrity of single crystal silicon material.

When IR materials are machined, machining strategy and parameters must be set carefully in order to reach high surface quality without sacrificing productivity. A good understanding of the deformation mechanism of single crystal IR materials has been a research subject for a long time [7]. High pressure at the tip of the fragile diamond tool is necessary so 
that the material goes through a phase transformation process and behaves like a metal, producing ductile chips, and thereby producing crack-free surfaces. It is known as ductile mode machining $[8,9]$. The critical chip thickness, beyond which cracks reach the machined surface and cannot be cleaned in successive machining passes, has been observed to increase with increasing negative rake angle [10, 11]. Increasing rake angle increases the thrust forces. When the high pressure is released, an amorphous layer of silicon forms on the surface during material recovery, and its thickness is directly related to the machining conditions (feed and depth of cut) and diamond tool geometry and rake angle [12]. Large negative $\left(20^{\circ}-50^{\circ}\right)$ rake angle diamond tools are usually used in diamond machining of single crystal silicon with the aim of increasing hydrostatic pressures at the cutting zone. Rake angles larger than $50^{\circ}$ result in debris accumulation problem in front of the cutting edge. In addition to rake angle, cutting edge radius, nose radius, and waviness of the nose radius of the diamond tool are other factors known to affect surface roughness significantly.

Diamond machining parameters and tool geometry affect the tool-work material contact conditions and significantly influence the subsurface integrity of the machined surface. Yan et al. [12] investigated the subsurface damage in silicon using laser micro Raman spectroscopy and cross-sectional transmission electron microscopy (TEM). They concluded that thickness of the machining-induced amorphous layer strongly depends on the rake angle and depth of cut. Yan et al. [13] performed nano scale plunge cutting experiments on silicon using different tool rake angles at different crystal directions. They observed that critical depth of cut increased with increasing rake angle to negative $45^{\circ}$. It must be noted that plunge cutting experiments were performed at low cutting speed. Cutting speed affects the thermal aspects of the machining process. Wang et al. [14] studied the influence of anisotropy of machined surfaces during diamond turning of silicon and observed that tools with $-40^{\circ}$ rake angle yielded better results that $-25^{\circ}$ rake angle tools. They related the improvement to increasing number of dislocations during plastic deformation. Patten and Gao [15] increase the rake angle from $-45^{\circ}$ to $-85^{\circ}$ and observed the increase in thrust forces and cutting angles. DurazoCardenas et al. [16] studied the diamond tool wear and observed that $-25^{\circ}$ rake angle yielded better performance compared to $-40^{\circ}$ rake angle. They also indicated the influence of specific diamond gem quality used in the experiments. Fang and Venkatesh [17] used a $0^{\circ}$ rake angle tool but selected the uncut chip thickness to be less than tool edge radius. Therefore, the effective rake angle was also negative. They obtained better surface finish compared to $-25^{\circ}$ rake angle tool. Mir et al. [18] recently investigated the influence of rake angle on diamond turning of silicon. No direct correlation between tool performance and rake angle was observed. They found that diamond tool with a negative $30^{\circ}$ rake angle performed poorly during experiments compared to negative $25^{\circ}$ and $40^{\circ}$.
It is a challenge to find optimized process conditions for the machining of silicon that will yield high surface quality and low subsurface damage. The nose radii of chamfered diamond tools have a circular profile whereas the large negative rake angle diamond tools have an elliptical form which is due to diamond tool grinding process. As a result, the rake angle along the nose radius remains constant in chamfered tools. In addition, due to zero rake angle on the top face of the tool, application of cutting fluid is easier which helps evacuating silicon debris away from cutting zone. Therefore, investigating the influence of chamfer angle may help understanding the relationship between process parameters and surface integrity. This study uses single point diamond turning tests with chamfered diamond tools together with areal surface characterization and subsurface damage detection techniques to investigate the influence of chamfer angle and process conditions on the surface integrity of single crystal silicon.

\section{Experimental setup}

An ultra-precision diamond turning machine Moore Nanotechnology 350 FG was used in the experiments. Figure 1 shows the experimental setup where a polished silicon work material having (100) crystal plane and $50 \mathrm{~mm}$ diameter with $3 \mathrm{~mm}$ thickness was placed on a vacuum chuck. Nanoindentation tests were conducted to measure the hardness $(1286 \mathrm{HV})$ and elasticity modulus (168 GPa) of the sample. Machining experiments were conducted under heavy use of coolant (odorless mineral spirit). Machined surfaces were analyzed using confocal laser microscope Keyence VKX110 (with $100 \times$ objective lens), white-light interferometer (NewView-7200, Zygo Corporation), and a laser microRaman spectrometer (WITec alpha series, laser wavelength of $532 \mathrm{~nm}$, and $50 \times$ objective lens with NA 0.75 resulting around $\sim 865 \mathrm{~nm}$ laser spot size).

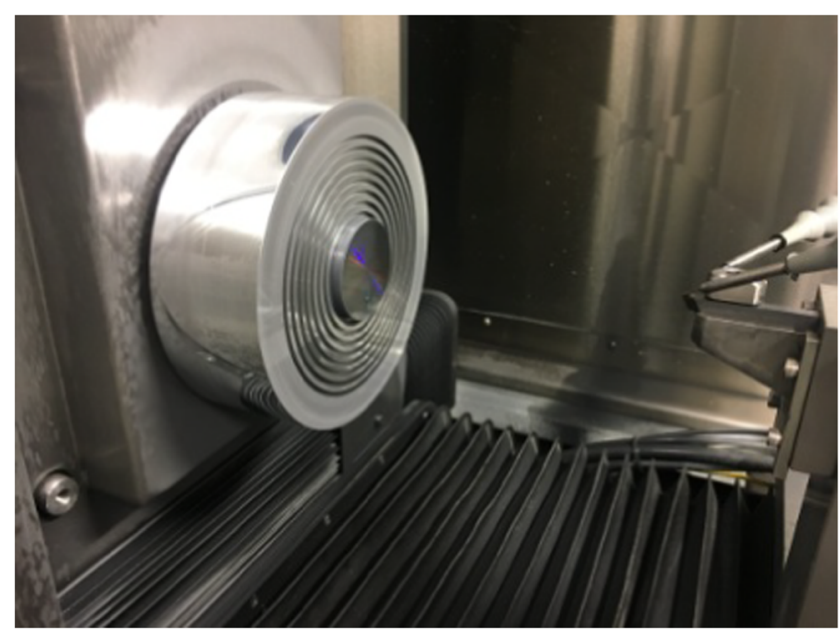

Fig. 1 Diamond turning experimental setup 
Chamfered single crystal diamond tools were used in this study. Chamfered tools have the ability to keep negative rake angle constant along the nose radius of the tool and thereby maintaining uniform chip formation. They also tend to accumulate fewer chips on the rake face during machining since only the cutting edge has negative rake angle. Design parameters of chamfered diamond tools are chamfer angle and width. In this study, chamfered tools having $20^{\circ}, 30^{\circ}$, and $45^{\circ}$ chamfer angle with $\sim 2-3 \mu \mathrm{m}$ chamfer width were used (ALMT, Japan). Nose radius of the tools was $0.53 \mathrm{~mm}$. Waviness along the cutting edge is less than $0.5 \mu \mathrm{m}$, clearance angle of $10^{\circ}$. Figure $2 \mathrm{a}$ shows the tip image of diamond tools where the chamfer land can be seen. Figure $2 b$ shows the machining parameters as feed $(f)$ and depth of cut $\left(a_{\mathrm{p}}\right)$. Uncut chip thickness varies with angle $\theta$ along the nose radius $(R)$. If the maximum value of uncut chip thickness $\left(t_{\mathrm{u}}\right)$ is less than the chamfer width $(L)$, only the chamfered region of the tool performs the cutting operation.
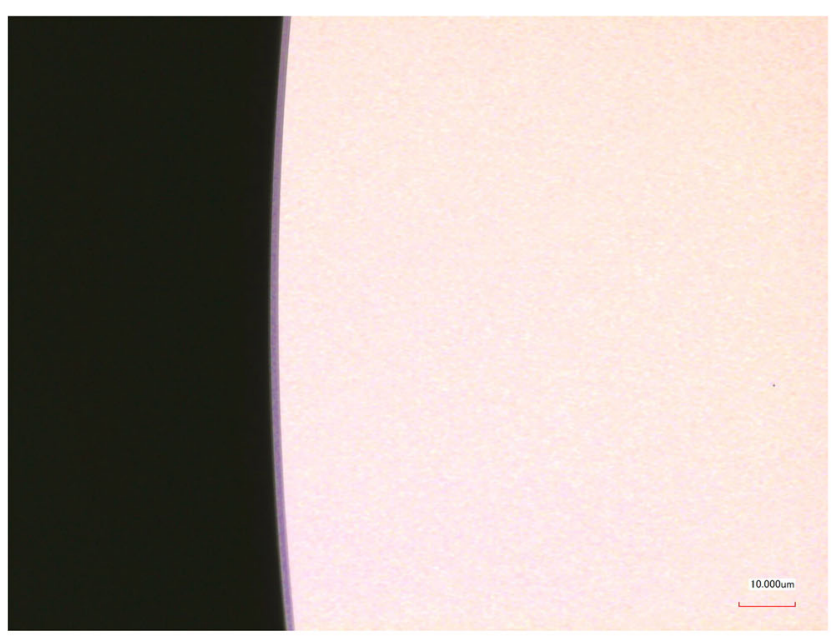

(a)

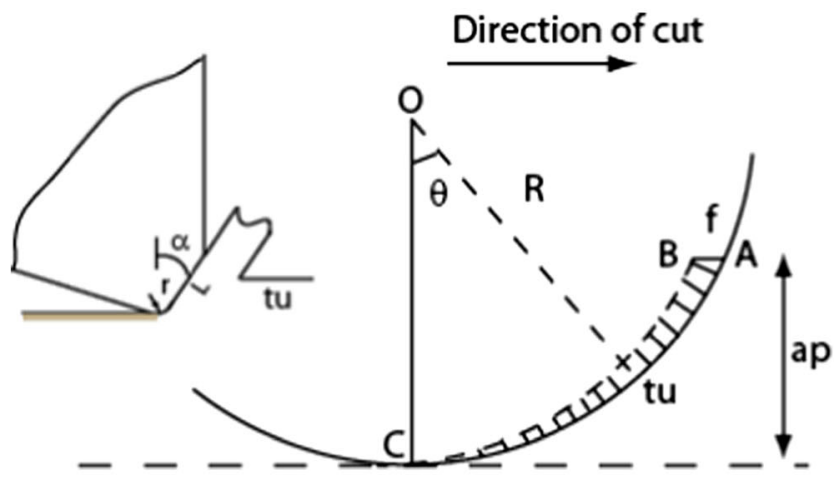

(b)

Fig. 2 a Chamfered diamond tool edge profile and $\mathbf{b}$ tool and process parameters

\section{Influence of chamfer angle on surface topography and integrity}

In the experiments, polished silicon lenses were machined at different depth of cut and feed conditions as shown in Table 1 . The aim is to mimic varying contact conditions typical during machining of freeform surfaces and eliminate the influence of machining-induced subsurface damage at each machining pass. Spindle speed was kept constant at $2000 \mathrm{rpm}$. Different polished silicon samples were used for each chamfer angle in experiments.

Figure 3 explains the first and second phases of the experiments. Regions of $2 \mathrm{~mm}$ length were machined. In the first phase (phase I in Table 1), depth of cut decreased from 10 to $4 \mu \mathrm{m}$ at varying feeds. In the second phase of the tests, a constant feed rate and spindle speed $(2 \mu \mathrm{m} / \mathrm{rev}$ and $2000 \mathrm{rpm}$ ) were used to machine the stepped surface from previous tests which allows for investigating the influence of increasing depth of cut $(4-6-8-10-12 \mu \mathrm{m})$ on the surface roughness and subsurface damage. In the third phase, depth of cut was kept at $2 \mu \mathrm{m}$ and feed was increased from 1 to $3 \mu \mathrm{m} / \mathrm{rev}$ on the remaining part of the polished surface. The last phase was only performed with $30^{\circ}$ chamfered tools due to limited availability of the tools. Machining conditions were selected based on practical silicon cutting parameters.

Surface topographies of silicon samples were investigated using both confocal laser topography and scanning white light interferometer. Measurement data were processed on Mountains Map software 7.4 based on ISO 25178 standard [19]. First, measurement outliers were filtered out. Then, leveling of the measured data was performed using least square plane method. A spatial smoothing filter (filter size $3 \times 3$ ) was then applied. Finally, a Gaussian filter with 8 - $\mu \mathrm{m}$ cut-off was applied to

Table 1 Experimental conditions

\begin{tabular}{llllll}
\hline Phase & Exp. \# & $\begin{array}{l}\text { Feed } \\
(\mu \mathrm{m} / \\
\text { rev })\end{array}$ & $\begin{array}{l}\text { Depth } \\
\text { of cut } \\
(\mu \mathrm{m})\end{array}$ & $\begin{array}{l}\text { Spindle } \\
\text { speed } \\
(\mathrm{rpm})\end{array}$ & $\begin{array}{l}\text { Feed rate } \\
(\mathrm{mm} / \\
\mathrm{min})\end{array}$ \\
\hline I & 1 & 1 & 10 & 2000 & 2 \\
& 2 & 0.84 & 8 & 2000 & 1.6 \\
& 3 & 0.7 & 6 & 2000 & 1.4 \\
& 4 & 0.56 & 4 & 2000 & 1.1 \\
II & 1 & 2 & 4 & 2000 & 4 \\
& 2 & 2 & 6 & 2000 & 4 \\
& 3 & 2 & 8 & 2000 & 4 \\
& 4 & 2 & 10 & 2000 & 4 \\
& 5 & 2 & 12 & 2000 & 4 \\
& 1 & 1 & 2 & 2000 & 2 \\
& 2 & 1.4 & 2 & 2000 & 2.8 \\
& 3 & 2 & 2 & 2000 & 4 \\
& 4 & 3 & 2 & 2000 & 6 \\
\hline
\end{tabular}


Fig. 3 Experiment strategy (phase I top, phase II bottom) and machined silicon sample
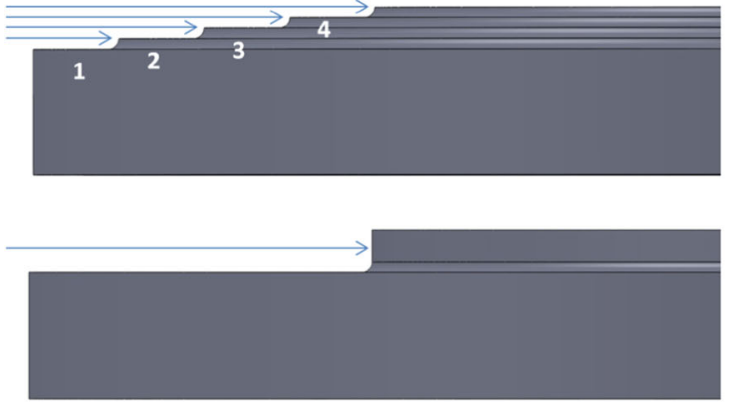

separate roughness (S-L) and waviness (S-F) surfaces. Measurement sample size was $144 \mu \mathrm{m} \times 108 \mu \mathrm{m}$. Figure 4 shows the surface micrographs for $20^{\circ}$ and $30^{\circ}$ tools under the first phase and third (I-3) experimental conditions where no pitting damage was observed on the surface.

Figure 5 shows areal surface roughness $(\mathrm{Sa})$ and maximum height of the surface $(\mathrm{Sz})$ values for each machining case in

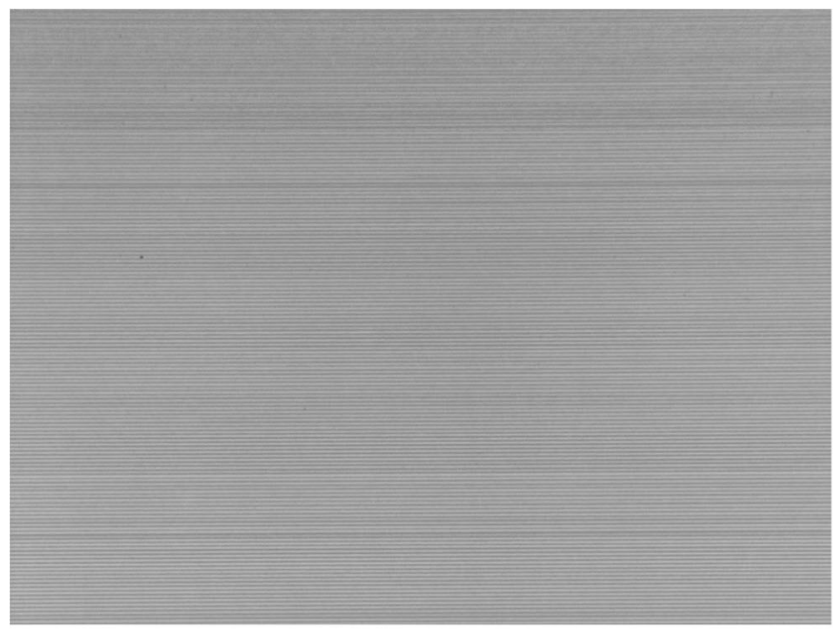

(a)

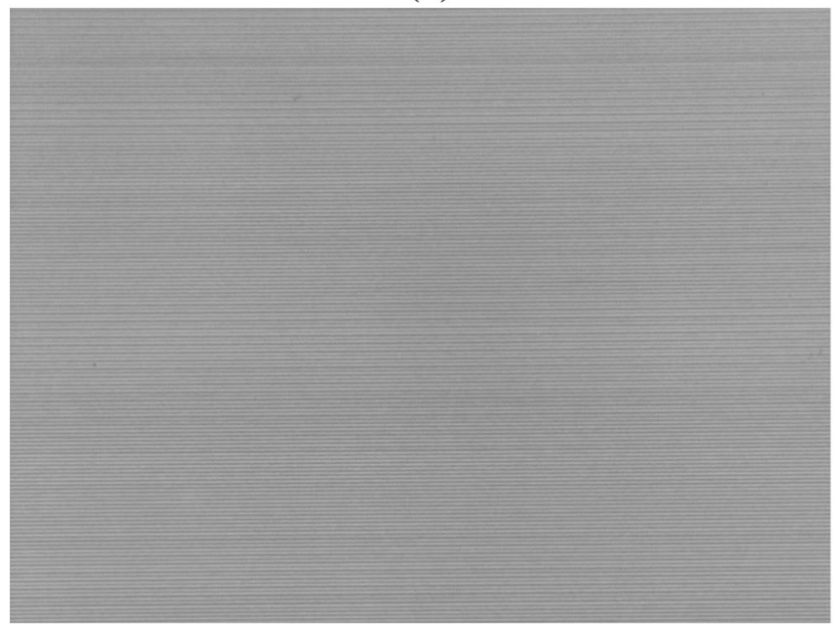

(b)

Fig. 4 Surface micrograph for $\mathbf{a} 20^{\circ}, \mathbf{b} 30^{\circ}$ chamfered tool in experiment \#I-3 phase I. Based on the results, in terms of $\mathrm{Sa}, 30^{\circ}$ chamfered tool yielded overall better results compared to $20^{\circ}$ and $45^{\circ}$ diamond tools. A similar trend was observed for root mean square height roughness, Sq where the values were around $25 \%$ more than Sa. The best result obtained at second experimental case for all tools. In experiments \#3 and 4, as depth of cut and feed decreased further, the surface roughness values did not improve compared to experiments \#1 and 2. According to maximum height of the surface (Sz) measurements, $20^{\circ}$ and $30^{\circ}$ tools yielded better results than $45^{\circ}$ chamfered diamond tool. It must be noted that at low uncut chip thickness values, due to the cutting edge radius of the tool (around $50 \mathrm{~nm}$ ), the effective rake angle increases, which hinders the surface generation. In addition, size effect issues are likely to initiate at such conditions.

In the second phase of the experiments, the silicon samples were machined at constant feed $(2 \mu \mathrm{m} / \mathrm{rev})$ and varying depth of cut (4-6-8-10-12 $\mu \mathrm{m})$ conditions as explained in Fig. 3. During these experiments, ductile, ductile-to-brittle transition, and brittle machining modes were observed, depending on the crystal direction and machining parameters as shown in Fig. 6.

At low depth of cuts ( 2 and $4 \mu \mathrm{m})$, machining was performed in ductile mode. Surface roughness started to deteriorate at $6 \mu \mathrm{m}$ and transitioned into brittle mode at depth of cut above $8 \mu \mathrm{m}$. The resulting surface yields a typical four-fold symmetry pitting damage arms which is typical for silicon

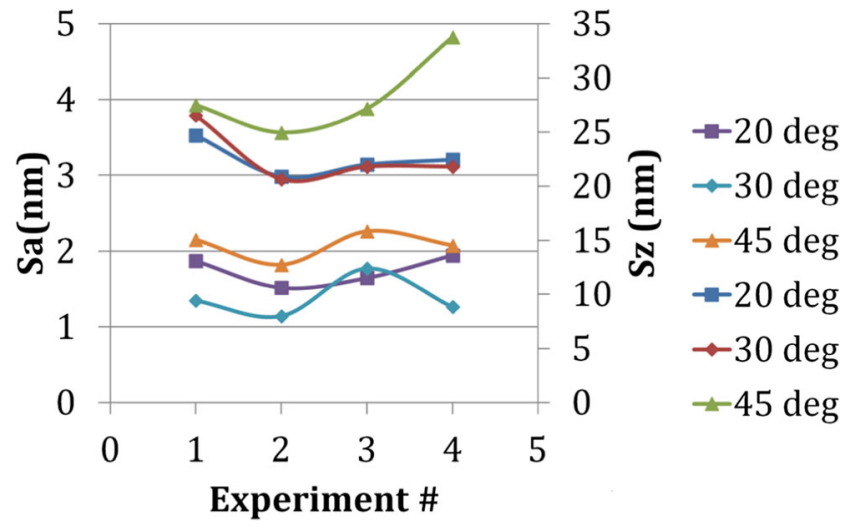

Fig. 5 Areal surface roughness and maximum height of the surface as function of different experiments 


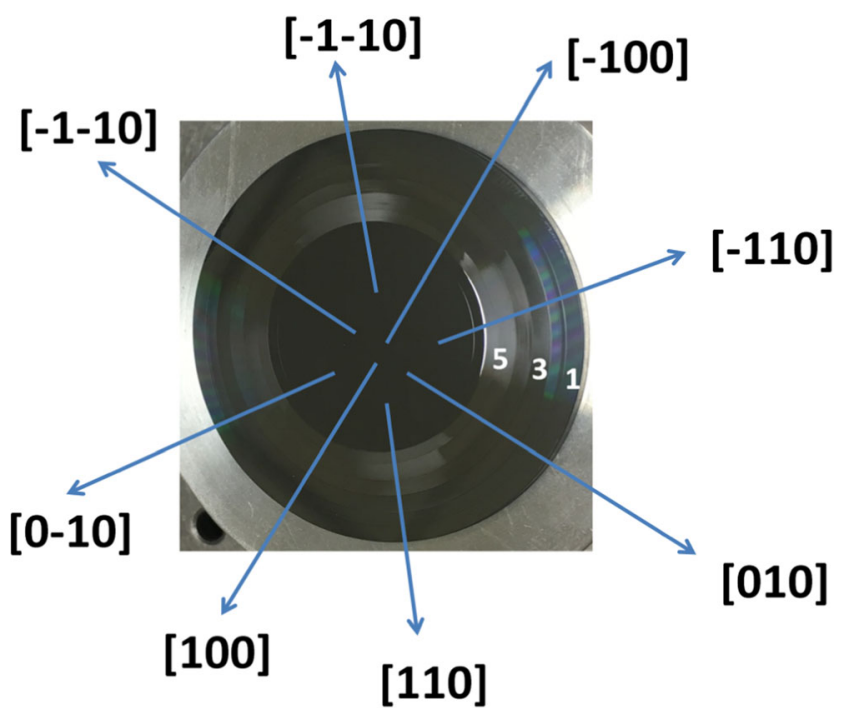

Fig. 6 Machined sample surface after second phase of the experiments (experimental conditions 1-5 are shown on the figure)

with (100) crystal plane orientation as shown in Fig. 6. Critical depth of cut can be identified to be between 6 and $8 \mu \mathrm{m}$ for

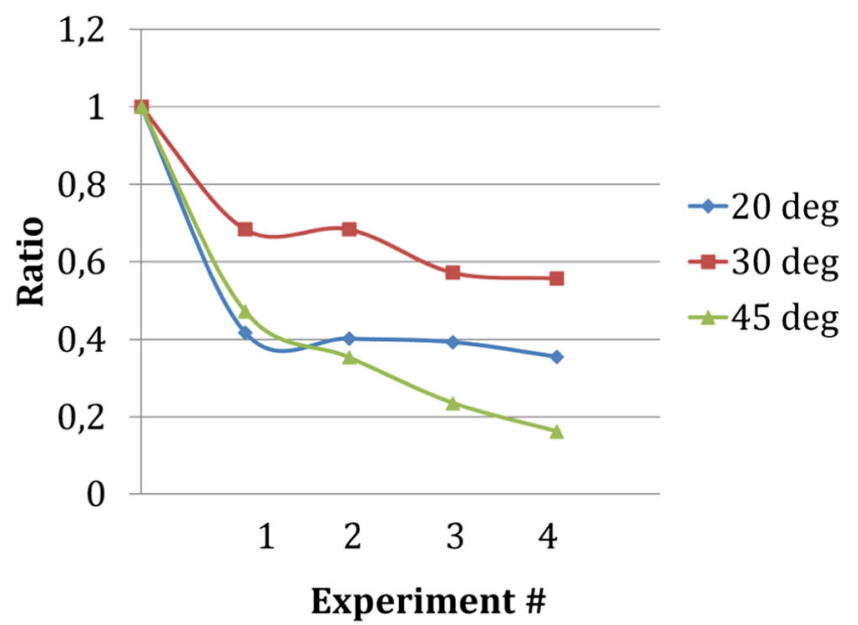

Fig. 8 Intensity ratio calculated from laser micro Raman measurements

feed of $2 \mu \mathrm{m} / \mathrm{rev}(4 \mathrm{~mm} / \mathrm{min})$ for all tools where machining transitioned from ductile to brittle mode.

Laser micro Raman tests were performed for all machining experiments in phases I and II. Figure 7 shows the Raman spectrum of machined surfaces corresponding to Exp \#I-3 and I-4 for
Fig. 7 Raman spectrum of the machined surfaces under experimental conditions a experiment \#I-3 and $\mathbf{b}$ experiment \#I-4

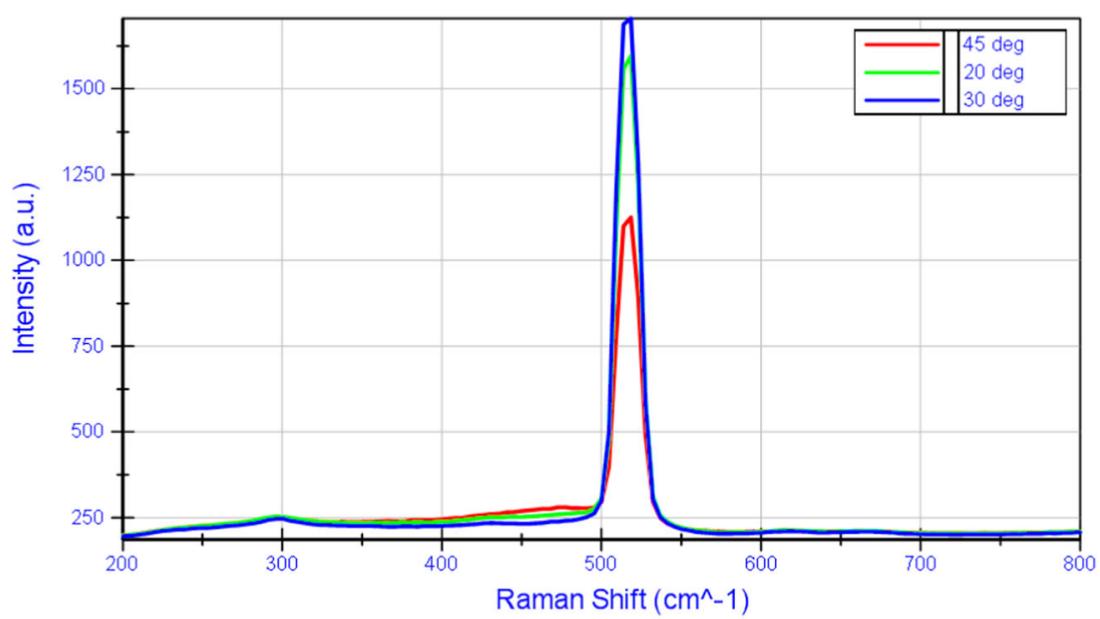

(a)

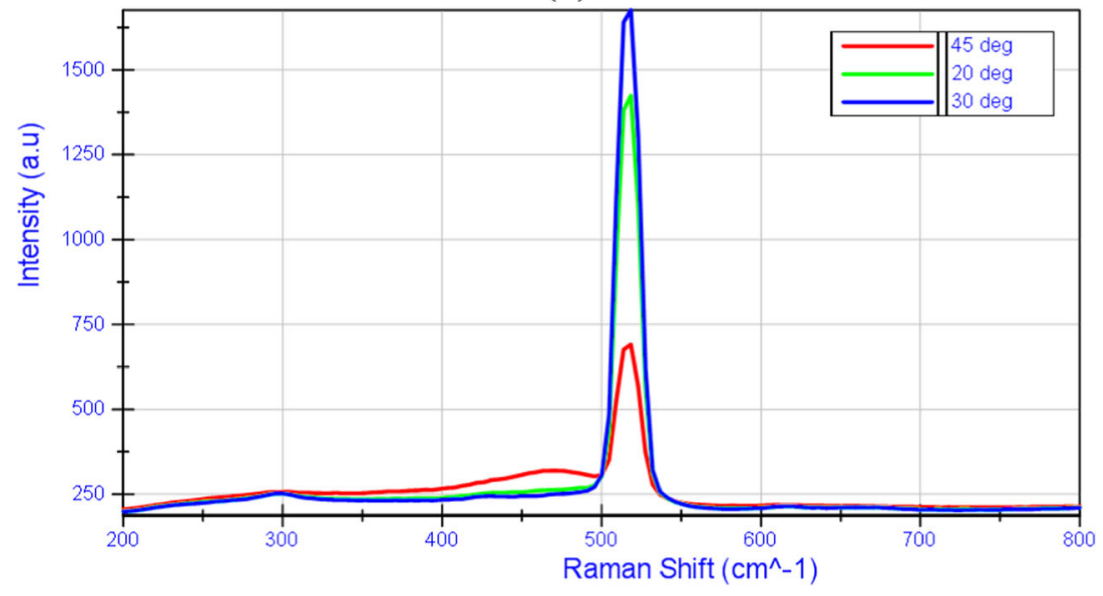

(b) 
Fig. 9 Influence of increasing depth of cut on Raman shift with $30^{\circ}$ tool

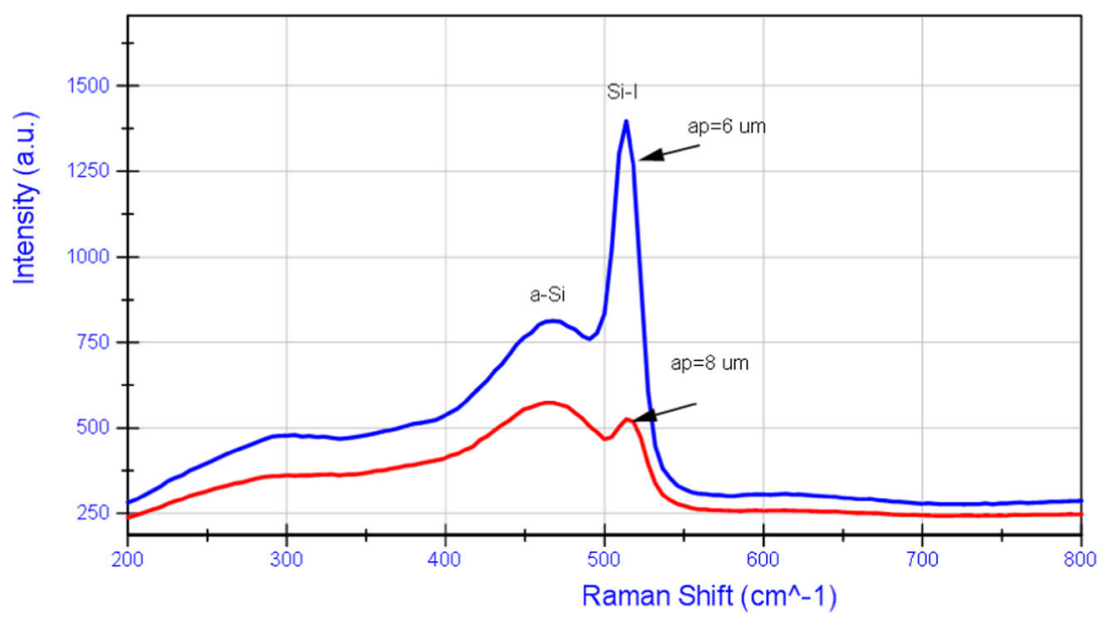

all tools. In Fig. 7a, for Exp \#I-3, there is a sharp peak at $521 \mathrm{~cm}^{-1}$ and no significant peak at other Raman shifts for all tools. It indicates that the structural changes are small and the Raman measurement system used here could not detect any changes. However, peak intensity values are different, with the

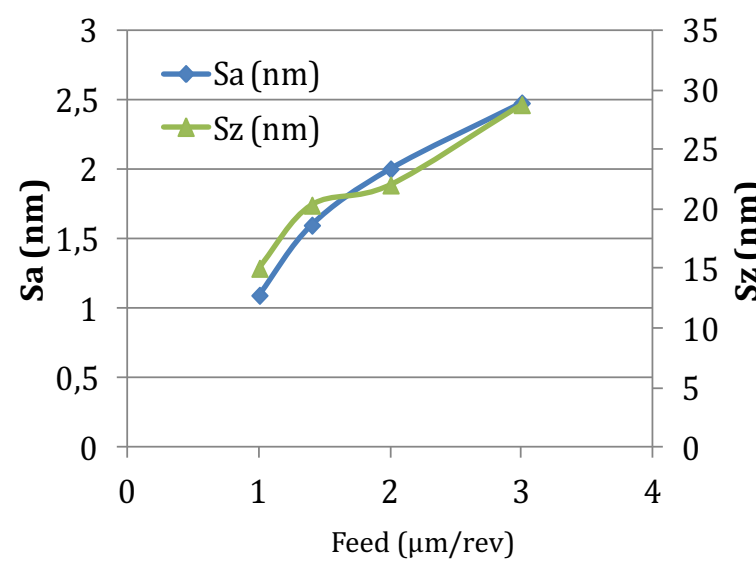

(a)

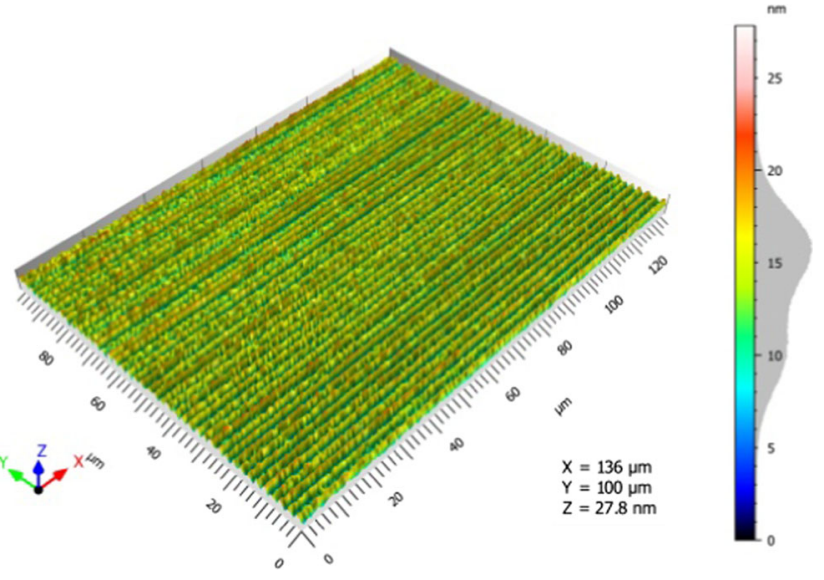

(b)

Fig. 10 a Influence of feed on $\mathrm{Sa}$ and $\mathrm{Sz}$ for $30^{\circ}$ chamfer angle and $\mathbf{b}$ surface topography for $3 \mu \mathrm{m} / \mathrm{rev}$ and $2 \mu \mathrm{m}$ depth of cut highest at $30^{\circ}$ and lowest at $45^{\circ}$. In Fig. $7 \mathrm{~b}$, while similar measurements were obtained for $20^{\circ}$ and $30^{\circ}$, a small peak at $470 \mathrm{~cm}^{-1}$ for $45^{\circ}$ indicates that a thin layer of silicon was transformed into amorphous state (a-Si). It must be noted that feed and depth is lower in Exp\#I-3 than Exp \#I-4. There seems to be a correlation between Raman measurements and $\mathrm{Sz}$ measurements on the surface. Yan et al. [20] proposed a method to estimate the thickness of the amorphous layer by using Raman intensity ratio information. A similar approach has been adopted in this study. Figure 8 shows the intensity ratio for each tool at four experimental conditions in finish machining tests. Intensity level obtained at the polished surface of the silicon material was considered as the reference value, and peak intensity values measured from the machined surfaces were considered to calculate a relative intensity ratio for each case. According to results, the $30^{\circ}$ chamfered diamond tool has a higher ratio for all experimental cases, indicating a smaller effect on the surface structure. With decreasing feed and depth of cut from finishing experiments \#I-1 to \#I-4, as Sz tends to increase (shown in Fig. 5), the intensity ratio also decreases. For $45^{\circ}$ tool, $\mathrm{Sz}$ value around $25-30 \mathrm{~nm}$ may be the limit for amorphous phase formation based on Figs. 5 and 7.

Figure 9 shows the Raman measurements for second phase of experiments that machined large depth of cuts. As depth of cut increased from 4 to $6 \mu \mathrm{m}$, amorphous layer formation on the surface increases significantly as evidenced from the peak at $470 \mathrm{~cm}^{-1}$. When the depth of cut further increased from 6 to $8 \mu \mathrm{m}$, intensity of the peak at $521 \mathrm{~cm}^{-1}$ corresponding to Si-I significantly decreases and machined surface mostly transforms into amorphous phase. Phase transformation is due to the high pressures applied by the tip of the diamond tool on the silicon surface. It is important to maintain pressure during machining more than $10 \mathrm{GPa}$ to obtain ductile chip formation [12]. On the other hand, exceedingly high pressures result in micro cracks on the surface. Increasing depth of cut usually leads to lower machining pressure since the contact area between the tool and the work material increases 
Fig. 11 Summary of machining characteristics with $30^{\circ}$ chamfered diamond tool

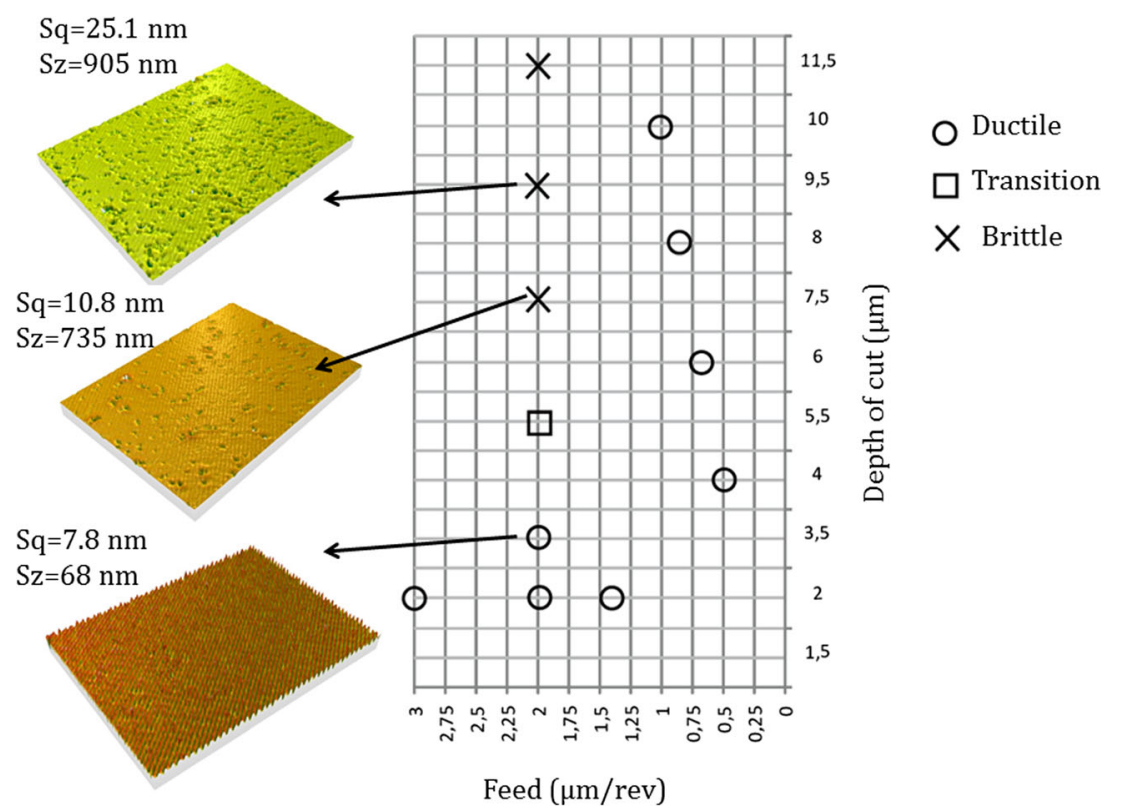

and average machining forces decrease due to brittle fractures occurring during machining.

\section{Influence of feed on surface topography and integrity}

Additional tests (third phase in Table 1) were conducted to validate the results obtained with $30^{\circ}$ chamfered tool on the top surface of the silicon to observe the influence of increasing feed on surface roughness. Depth of cut was kept constant at $2 \mu \mathrm{m}$, spindle speed as kept at $2000 \mathrm{rpm}$, and feed increased from 1 to $1.4,2$, and $3 \mu \mathrm{m} / \mathrm{rev}$. Figure 10a shows the influence of feed on surface topography. Figure $10 \mathrm{~b}$ shows the S-L surface topography at feed of $3 \mu \mathrm{m} / \mathrm{rev}$. Areal surface roughness (Sa) and maximum height of the surface $(\mathrm{Sz})$ increase with increasing feed, as expected. The areal surface roughness $\mathrm{Sa}=1 \mathrm{~nm}$ obtained at $1 \mu \mathrm{m} / \mathrm{rev}$ is in close agreement with the previous tests in the literature [11] indicating the equivalent performance of chamfered tools.

Figure 11 shows the summary of experimental studies for chamfered diamond tools. In this figure, the influence of depth of cut and feed on machining characteristics can be seen. The interplay between feed and depth of cut can be seen as increasing feed requires depth of cut to be decreased. At low feed, depth of cut can be increased up to $10 \mu \mathrm{m}$ in ductile model cutting.

\section{Conclusions}

In this study, ultra-precision machining of single crystal silicon was performed with chamfered diamond tools.
Influence of chamfer angle and process parameters (feed and depth of cut) on areal surface roughness and subsurface damage has been investigated using an experimental approach. Based on the results obtained at experimental conditions considered in this study, under finish machining conditions, diamond tool with $30^{\circ}$ chamfer angle performed better than $45^{\circ}$ chamfer angle diamond tool. In terms of areal surface roughness values, performance of $30^{\circ}$ chamfer angle diamond tool was observed to be slightly better than $20^{\circ}$ chamfer diamond tool. Using $30^{\circ}$ chamfer angle tool at finish machining conditions of $2 \mu \mathrm{m}$ depth of cut and $1 \mu \mathrm{m} /$ rev feed yielded areal surface roughness values around $1 \mathrm{~nm}$, which satisfies the high standards in the optics industry. Low subsurface damage was detected at finish machining conditions with the measurement device used in this study. Based on higher feed and depth of cut experiments with diamond tool having $30^{\circ}$ chamfer angle, pitting damages on the machined surface appear around 7-8 $\mu \mathrm{m}$ depth of cut value resulting in low surface integrity. Raman analysis of the machined surfaces indicated the phase transformation of silicon into an amorphous phase.

Acknowledgments The author would like to thank the Ministry of Development of Turkey (HAMIT-Micro System Design and Manufacturing Research Centre).

Funding information This work was financially supported by the Turkish Scientific and Technological Research Council of Turkey (TUBITAK) through project 115M699.

Publisher's Note Springer Nature remains neutral with regard to jurisdictional claims in published maps and institutional affiliations. 


\section{References}

1. Fang FZ, Zhang XD, Weckenmann A, Zhang GX, Evans C (2013) Manufacturing and measurement of freeform optics. CIRP Ann Manuf Technol 62:823-846

2. Fang FZ, Zhang XD, Gao W, Guo YB, Byrne G, Hansen HN (2017) Nanomanufacturing - perspective and applications. CIRP Ann Manuf Technol 66:683-705

3. Owen J, Davies M, Schmidt D, Urruti E (2015) On the ultraprecision diamond machining of chalcogenide glass. CIRP Ann Manuf Technol 64:113-116

4. Owen JD, Troutman JR, Harriman TA, Zare A, Wang YQ, Lucca DA, Davies MA (2016) The mechanics of milling of germanium for IR applications. CIRP Ann Manuf Technol 65:109-112

5. Mukaida M, Yan J (2017) Ductile machining of single-crystal silicon for microlens arrays by ultraprecision diamond turning using a slow tool servo. Int J Mach Tools Manuf 115:2-14

6. Tang X, Nakamoto K, Obata K, Takeuchi Y (2013) Ultraprecision micromachining of hard material with tool wear suppression by using diamond tool with special chamfer. CIRP Ann 62:51-54

7. Goel S, Luo X, Agrawal A, Reuben RL (2015) Diamond machining of silicon: a review of advances in molecular dynamics simulation. Int J Mach Tools Manuf 88:131-164

8. Blake PN, Scattergood RO (1990) Ductile-regime machining of germ5anium and silicon. J Am Ceram Soc 73(4):949-957

9. Lucca DA, Chou P, Hocken RJ (1998) Effect of tool edge geometry on the nanometric cutting of Ge. CIRP Ann Manuf Technol 47(1): $475-478$

10. Shibata T, Fujii S, Makino E, Ikeda M (1996) Ductile-regime turning mechanism of single crystal silicon. Precis Eng 18:129-137
11. Leung TP, Lee WB, Lu XM (1998) Diamond turning of silicon substrates in ductile-regime. J Mater Process Technol 73(1-3):42-48

12. Yan J, Asami T, Harada H, Kuriyagawa T (2009) Fundamental investigation of subsurface damage in single crystalline silicon caused by diamond machining. Precis Eng 33:378-386

13. Yan J, Asami T, Harada H, Kuriyagawa T (2012) Crystallographic effect on subsurface damage formation in silicon microcutting. CIRP Ann Manuf Technol 61:131-134

14. Wang M, Wang W, Lu Z (2012) Anisotropy of machined surfaces involved in the ultra-precision turning of single-crystal silicon-a simulation and experimental study. Int J Adv Manuf Technol 60(5): 473-485

15. Patten JA, Gao W (2001) Extreme negative rake angle technique for single point diamond nano-cutting of silicon. Precis Eng 25(2): $165-167$

16. Durazo-Cardenas I, Shore P, Luo X, Jacklin T, Impey SA, Cox A (2007) 3D characterisation of tool wear whilst diamond turning silicon. Wear 262(3-4):340-349

17. Fang FZ, Venkatesh VC (1998) Diamond cutting of silicon with Nanometric finish. CIRP Ann Manuf Technol 47(1):45-49

18. Mir A, Luo X, Cheng K, Cox A (2017) Investigation of influence of tool rake angle in single point diamond turning of silicon. Int $\mathrm{J}$ Adv Manuf Technol 94:2343-2355. https://doi.org/10.1007/s00170017-1021-7

19. Characterisation of Areal Surface Texture Richard Leach Editor Springer, ISBN 978-3-642-36458-7

20. Yan J, Asami T, Kuriyagawa T (2008) Nondestructive measurement of machining-induced amorphous layers in single-crystal silicon by laser micro-Raman spectroscopy. Precis Eng 32:186-195 